\title{
SOCIAL SEMIOTICS IN VISUAL COMMUNICATION APPLIED IN ADVERTISEMENTS OF BANKING PRODUCTS AND SERVICES
}

\author{
Kinga KowALEWSKA, MARTA KOSZKO
}

\section{Introduction}

Visual communication is a complex process, which requires broad knowledge of semiotics. Therefore, the advertising industry has to take into consideration semiotic notions in order to create a successful message. The choice of images for a particular advertising campaign relies on certain strategies. The analysis of images from adverts in banking industry revealed that these advertising strategies apply to a matrix whose elements can be treated as a step-by-step approach to the analysis of advertising in a number of branches, not restricted to banking industry. These elements constitute crucial notions in semiotics, i.e. denotation, connotation, cultural context and qualisigns. The created matrix may reflect how the meaning of certain concepts can be developed.

In order to understand the process of meaning-making in advertising, the notions of advertising itself and social semiotics need to be briefly scrutinized. They are naturally intertwined with the notions of a code, semiotic resources and culture. All of them constitute basic elements of visual communication.

\section{Advertising}

Advertising can be treated as a process of persuasion aiming at informing, convincing and selling. With the growing competition on the market, the techniques naturally must have become more and more sophisticated. However, the 
basic principles and purposes remain the same. For Cook (1992), it would be to persuade people to buy some products. For Durant and Lambrou (2009), to transfer information about some goods, their availability, quality and functioning. Yet for Dyer, (1982) the goal of advertising is “(...) to introduce a wide range of consumer goods to the public and thus to support the free market of economy (...)". Saren et al. (2007) points to the fact that adverts always have to refer to a system of meaning which already exists. Otherwise, without such signification, the advertised product would have no meaning. This system of meaning will here be referred to as a cultural context and the knowledge of codes.

Advertising takes a number of different forms and utilizes various media. However, as in the present discussion the emphasis in placed on images appearing in print adverts, the knowledge of certain facts concerning the perception of printed advertisements seems crucial. Namely, the body copy of advertisements is roughly read by $5 \%$ of readers in a usual magazine, and in a specialist magazine by $10 \%$. Moreover, most people on average take 1.5 second to read each printed advertisement, which means that there is time only to see the picture (Kwarciak, 1999). Additionally, pictures as such are easier and faster to read than words as they take less effort and give the eye freer movement. Therefore, the picture becomes a central element of press advertisement.

In order to understand the message transmitted in advertising the notions of social semiotics, codes and semiotic resources cannot be omitted. Advertising is in itself a "semiotic entity" (Najafian and Ketabi, 2011) and the creation of a successful message requires the consideration of the following aspects: "the environment of communication", "resources available to make the message", "phenomenon to be communicated" (Kress, 2010).

\section{Social semiotics and visual communication}

Advertising relies heavily on signs, which are building blocks of every visual message. No message in advertising can be therefore composed/designed without reference to semiosphere, i.e. Global Sign Arena (Puppel, 2010), as it imposes particular skills from the communicators (creators of advertising message). It the present discussion it is not however only necessary to refer to semiotics in general, so the study of signs, gestures or objects (Chandler, 2004), but predominantly to social semiotics, which allows for a much broader perspective in the analysis of the process of advert creation. In a very broad sense social semiotics can refer to "the study of signs in everyday life" (Cobley, 2010) or "the use of signs in specific social situations" (Chandler, 2004). In this paper specific social situations will refer to the realm of banking industry and particular strategies applied in the process of advert making, while the images are 
undoubtedly the signs. As Bignell (2002) states, images which are used in print advertisements create a particular system of signs and this system is necessary to understand the reality. Therefore, as the focus is placed on advertising the concept of social semiotics should not be separated from the notion of visual communication, whose basic principles are implemented in advert making. They are closely intertwined. Jewitt and Oyama (2004) put together the two notions and talk about "social semiotics of visual communication" which "involves the description of semiotic resources, what can be said and done with images (and other visual means of communication) and how the things people say and do with images can be interpreted." When analyzing some examples of visual communication in terms of social semiotics it should be noted that "any image (...) not only represents the world (whether in abstract or concrete ways), but also plays a part in some interaction and, with or without accompanying text, constitutes a recognizable kind of text (a painting, a political poster, a magazine advertisement, etc.)" (Jewitt and Oyama, 2004; after Kress and van Leeuwen, 1996). Therefore, advertising cannot be properly understood without semiotics considered. Every element of an advert is a sign, whether linguistic, e.g. words or iconic, e.g. images. They all carry some meaning (Bignell, 2002).

When discussing social semiotics and the process of meaning making, particularly in advertising, the concepts of denotation, connotation and qualisigns cannot be omitted. Denotation refers to the literal meaning of a sign, hence its meaning "would be broadly agreed upon by members of the same culture" (Chandler, 2004). Connotations on the other hand refer to "socio-cultural and personal associations (ideological, emotional etc.) of the sign". They are "determined by the codes to which the interpreter has access" (Chandler, 2004). Finally, the qualisigns can be defined as "a sign that draws attention to qualities possessed by the referent" (Danesi, 2002). They often function as symbols or visual metaphors determined by cultural experience.

\section{Codes and semiotic resources}

Semiotic analysis of advertisements cannot be performed without the reference to the notion of a code or semiotic resources. Both are perceived as crucial in the process of interpretation of a message. A code can be briefly defined as "a set of practices familiar to users of the medium operating within a broad cultural framework" (Chandler, 2004) and it is a basic element of communication "activated in various communication acts" (Puppel, 2013: 94). In the case of this discussion it is advertising which is seen as the medium of message transmission, while the set of practices can be compared to the techniques used by the creatives. Both the medium and the techniques and their final outcome (an ad- 
vert) have to be compatible with cultural context in which they operate. Codes seem to govern people's perception of reality and hence the following types can be distinguished: social codes (focus on verbal and nonverbal language, refer to behaviour and goods used); textual codes (include among others mass media codes - newspapers, television, photography); interpretative codes (refer to visual perception as well as codes which allow for coding and encoding of the message) (Chandler, 2004). These three types of codes have to co-exist to enable the reception of the messages sent from the surrounding space. However, these codes cannot function correctly without the specific kind of knowledge which allows for proper interpretation of the code. These are: the knowledge of the world, medium and the relationship between these two.

Except for 'codes', the concept of 'semiotic resources' is also used in the semiotic analysis of verbal and non-verbal message. Van Leeuwen (2005) emphasizes strongly the difference between 'semiotic resources' and a 'code' writing that semiotic resources are understood as "the actions and artefacts we use to communicate, whether they are produced physiologically - with our vocal apparatus; with the muscles we use to create facial expressions and gestures, etc. - or by means of technologies - with pen, ink and paper; with computer hardware and software; with fabrics, scissors and sewing machines, etc. Traditionally they were called "signs"". The use of semiotic resources is closely related to the social context. Although in each social context there operate some "rules or best practices" which guide the use of semiotic resources (Van Leeuwen, 2005), the users of semiotic resources can also use them freely without any rules or restrictions. This potential of semiotic resources can simply be described as "potential for making meaning" (Van Leeuwen, 2005). Each behaviour, action or material object can have several meanings also depending on the social context. As van Leeuwen (2005) explains: "studying the semiotic potential of a given semiotic resource is studying how that resource has been, is, and can be used for purposes of communication (...)". Therefore, in the case of this paper, understanding the semiotic potential of an image placed in an advert allows one to understand its various possible interpretations.

In the discussion concerning visual communication it cannot be forgotten that the knowledge of codes and understanding semiotic resources allow the recipients of the message understand the signs which form the visual message. Furthermore, both codes and semiotic resources as connected with social context are also intertwined with culture.

In discussions concerning codes or semiotic resources there appear frequent references to cultural context. Culture along with environment are inseparable building blocks of communication, which in this case appears in the form of advertising. Therefore in creating any kind of advertisement, hence a communication act, "a broader socio-cultural communicative context" (Puppel, 2013: 95) 
needs to be constantly updated and analyzed, as communicators - senders and receivers of advertising message - are "rooted in culture" (Puppel, 2013: 97). Unquestionably, culture serves as a point of reference in the interpretation of various practices, including any form of advertising.

Because the present paper looks at advertising from a semiotic point of view, a definition of culture with semiotics in focus can be suggested: "a culture can be defined as a kind of "macro-code", consisting of the numerous codes which a group of individuals habitually use to interpret reality" (Danesi, 1994). Visual communication, just as any other kind of communication, is strongly dependent both on culture and codes. People from a particular culture are able to read the meaning in advertising just through the prism of culture and its conventions. They understand the codes, their relationships and "contexts in which they are appropriate" (Chandler, 2004).

As the present discussion centers around advertising in a financial branch, it has been assumed that it takes three types of codes to determine the proper understanding the non-verbal message in an advertisement of a financial product. The first code can be translated into culture, which has already been defined in reference to code. Generally, it can be said that it is familiarity with convention present in every aspect of reality. This convention is realized by the use of symbols, rituals, traditions specific for a given culture (see Hofstede \& Hofstede, 2005 "Onion Model" of culture). This code helps identify the meaning and function of a particular object in a cultural reality. The second type of code concerns the knowledge of the convention of advertisement. The awareness of the purpose and general structure of advertisements helps identify them from among other texts and pictures and read them through the prism of their persuasive goal. The third type of code refers to the financial aspect itself. As a logotype or brand name of a bank is one of the most striking elements of an advertisement, the receiver knows what institution is advertised and may easily identify the financial context of interpretation.

The presented notions of codes or semiotic resources, social semiotics, visual communication and culture were all considered in the analysis of images used in advertisements from banking industry.

\section{Research part}

The starting point was to identify advertisements concerning abstract, intangible services (products). The financial sector proved to be fruitful in this respect as it offers loans, deposits, bank accounts, and other products which cannot be presented in a graphic form. Hence, there is a challenge for creatives to express them visually by the use of other notions - objects, which are tangible. 


\section{Aim and assumptions}

The main aim of the research was to analyze how abstract notions related to banking services are depicted with the use of tangible objects in advertisements and to show how these tangible objects (functioning as signs) can be translated through social semiotics.

\section{Research method}

The research method was content analysis, which focuses on communication process as depending on the understanding of the following elements: text, image and context. Although content analysis developed mainly in the political field, in the marketing area it may help define a specific pattern of communication between senders and receivers of advertising messages. This methodology used most frequently in the humanities, refers to semiotic aspects of meaning making.

\section{Data collection}

The research material was collected mainly in the first quarter of 2013 and comprised leaflets available in local branches of the following banks in Poland: Multibank, WBK, SGB, Bank Pocztowy, PKO SA, ING Bank Śląski, InvestBank, TL, Alior Bank, Aquarius, Raiffeisen Bank, Bank Pekao, Neobank, Millennium Bank. The remaining part of the material was collected in the form of press advertisements of City Bank, Lucas Bank, Invest-Bank, PKO BP, PKO $\mathrm{SA}, \mathrm{mBank}$. In order to unify terminology, we refer to both groups of research material as advertisements.

\section{Data interpretation}

It was decided to examine the data against a matrix which places image in a central position and examines it in four aspects such as: denotation, connotation/activity, cultural context, and qualisigns.

The main focus of the research was put on visual representation of ideas, therefore all the images from advertisements were examined against the abovementioned aspects. It has to be stressed that there is no clear-cut division between the categories and they may overlap. Therefore, we had to make a decision which aspect prevails in a given picture. 


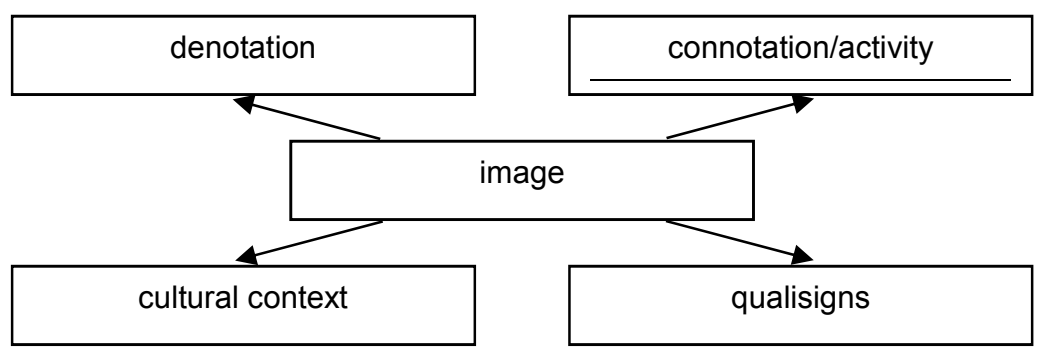

Fig. 1. The matrix of image interpretation

It has been assumed that the matrix can be applied in any research aiming at the analysis of advertisements for intangible products and may allow one to see how objects gain meaning when not complemented by text. This approach may prove particularly useful for copywriters and advertisers.

Before presenting the results of the research, the aspects constituting the matrix should be briefly described, even though some definitions have already been given above.

Denotation can be understood as a translation of a sign to its literal meaning, where the sign represents an idea or an object. Connotation may be analogically defined as a translation of a sign to meanings associated with it, suggested by an object or situation. Actions shown in the pictures express activities referring to the advertised product - they represent people using the product or performing activities which are possible thanks to the product. Further, the presence of cultural context helps identify specific meaning which without the knowledge of conventions, rituals, traditions or symbols characteristic for a given culture could be misunderstood or unnoticed. Lastly, qualisigns frequently function as symbols or visual metaphors and are usually determined by cultural experience.

\section{Research results}

\section{Denotation}

Banks offer a wide and diversified range of financial products. Deposits, insurances, loans, accounts - although apparently unconnected can be reduced to the lowest common denominator - money. They cannot be photographed due to their intangible nature, but money can. Taking interpretative codes into account, it could be said that in the European culture money traditionally takes the form of coins and banknotes, which are tangible object that can be easily pictured. The image of golden coins or paper banknotes is concrete and evocative and as such does not require any further process of interpretation. They both serve as 
symbols of banking services and financial industry. The analyzed research material also showed that both coins and banknotes are hardly depicted as a single item. Coins are usually presented either as a neat pile or, to the contrary, as an irregular heap of money. It seems that not only the very object carries a meaning but also its arrangement against other objects proves meaningful. For example, if a pile of coins is used as a foundation of the house, it can be translated into a statement that financial support is needed to build a house (advertisement for a mortgage).

In order to increase interpretative potential of signs, they tend to be presented in action (when used). One of the most common financial means apart from banknotes and coins is a credit card. This easily recognizable rectangular piece of plastic is frequently pictured while being used by human; it is held in hand (advert for a credit card), proudly shown (a discount programme), or stuck in a card terminal being in the centre of a financial action (a cash loan).

When objects are used as signs to build a more complex form and evoke more specific meanings or associations they belong to the second group identified in our research, which is connotation.

\section{Connotations/activities}

Taking into account the fact that an advertising message is directed to a large and differentiated group of receivers from the same socio-cultural background, connotations evoked by images on the leaflets should not be individual and personal as they are hard to predict, but rather as general and universal within a particular society as possible.

The analysis of the materials showed that while making a choice on the picture which should help elude certain associations, universal objects carrying widely recognizable symbolic meanings are taken into consideration. Another point was that connotations evoked by images related to money refer mostly to activities performed with money. Therefore, it seems necessary to present the most common objects which are used to evoke universal associations such as saving, growing, investing, transferring, and finally spending money.

Associations connected with saving money can be triggered by a few concepts. For example, one advertisement of a bank account shows a picture of a pink animal-shaped container with a narrow rectangular hole. Only having access to cultural experience and knowledge of convention it can be recognized as a money box - a container in which money is stored. A glass jar may be another example of an object associated with saving money, although it is culture-specific and may be considered old-fashioned. There are images presenting a traditional women's purse and this object gets symbolic meaning bringing saving rather than spending money into one's mind. Thus, it may be concluded that bank- 
ing products such as savings accounts, deposits, or loans are advertised and promoted with the help of such evocative signs as a money box, a glass jar, or a purse because these images allude to the properties of particular banking products.

The concept of growth is evoked by a rather universal notion of a plant. The idea of nature growing is commonly known in every culture, even in the regions where flora is non-existent due to unfavourable climate. In the picture from a leaflet advertising leasing services an image of a green plant growing from a bunch of golden coins is presented. A cash loan advertisement shows a picture of an old tree covered with green banknotes instead of leaves, which are sailing in the windy air. In the next advertisement (for a deposit) one can see a green plant growing in a row clay flowerpot. Only after a closer look one may recognize that the whole plant is in fact made from folded green banknotes, where the colour of leaves corresponds with the colour of banknotes.

Another group of associations is focused around a more advanced concept, which is the idea of investing money. One can invest in land, stock market, fixed property, or shares, however, the conducted research showed that in the leaflets and advertisements the representation of money investment includes precious metals, e.g. gold, and precious stones e.g. diamond, which possess high financial value regardless of the type of currency used. Even though investing in the stock market or shares relates to a more sophisticated financial system, and thus is more culture-specific, the image of golden coins or brilliant cut diamond does not need to be read against cultural code and becomes a universal symbol of investing.

Transferring money, another activity distinguished in the research, turns out to be highly culture-specific. It requires advanced technology and electronic devices, which are available in technologically developed parts of the world. Images which are designed to evoke associations with transferring money include: mobile phones, computers, netbooks, laptops - mostly shown while being used by a (smiling) human. As has been assumed, a receiver of an advertisement recognizes two codes in the process of interpretation: the one concerning the knowledge of the convention of advertisement and the other one referring to the financial aspect. Thus, the presence of a logo of a bank in the background of a picture in the leaflet makes it possible to deduce that, for example, a man sitting on a coach looking cheerfully into the laptop screen (an advert of online funds) is transferring money and not, for instance, playing an online game.

One of the most basic financial activities is spending money when purchasing some goods. The idea of spending, being an abstract notion, is expressed with the use of objects. The analyzed research materials proved that evoking denotation of spending money can be a complex process. In the simplest way, the association may be triggered by showing a shopping bag. On the level of denotation, a large shopping bag is nothing more than a colourful plastic or pa- 
per bag, however, when placed on a leaflet advertising banking services it is automatically moved to the level of connotation and translated into shopping. A woman carrying a bunch of shopping bags is the most commonly used image because it is easily translated into shopping, especially that women are thought to shop more than men (adverts for a credit card and a discount programme). Images of a credit card being slid through the terminal or a woman proudly presenting a fan of different colorful credit cards complement the group of most popular images signifying shopping.

Nevertheless, spending money may mean something more than plain shopping. There are certain projects demanding extensive sums of money to be spent, e.g. building or redecorating a house. Certain images are supposed to evoke connotations related to these projects, e.g. a house. The recurrent motive of a house is portrayed in a number of ways: as a shape (loan), a sketch of a house under construction (mortgage), model (loan) or even as a symbolic snail shell with doors, windows and a chimney drawn on it (mortgage).

Travelling is a good example of another costly activity appearing on the bank leaflets. Travelling or journey is intangible; therefore it again requires a connoting object. In this case different means of transport refer to travel costs but also to the very idea of moving, being dynamic, moving in a desired direction and eventually reaching the destination of all sorts. In the advertisement of loans for firms one can see a close-up of a plane jet engine and a fragment of a plane wing. This simple image is suggestive enough to evoke associations with travelling over long distances by air. Another picture, advertising accounts for firms, shows a person climbing airplane stairs with a neat suitcase, which also brings flying to one's mind.

Apart form travelling by air, there is a large group of images alluding to road journeys. For example, a pension package is promoted by an image of a young couple travelling in a convertible car on a wide empty road toward the setting sun. An advertisement for car loans uses a picture of an entirely empty though winding road and investment funds - a road sign signifying the beginning of a new traffic lane with clear blue sky in the background.

The above mentioned instances show that spending money is the most extensive group of activities performed with money and it comprises two large subgroups, namely shopping and travelling.

\section{Cultural context}

At the very beginning the concept of culture was defined as an umbrella term for numerous codes helping interpret reality (Danesi, 1994). Culture as such is built upon the notion of conventions and rituals and knowing them is crucial for 
proper interpretation of the signs. This approach has been adopted in order to formulate another category of objects which advertise banking products and services. The following examples can be rightly interpreted only within a narrow cultural context. The narrow cultural context assumes that the interpretation of these signs may be different depending on a continent, country or even a given region. The collected material showed us that certain images are culture-specific and will "work" only in some cultures. Moreover, these images may gain different meaning when placed in an advertisement from a different branch. Examples of such images include: a wedding cake, a Chinese dragon, and a birthday gift box.

An image of a box with a wedding cake drawn at the front is utilized in an advert promoting government stocks. The box is open and there is a wedding cake topper with a bride and groom sticking out of it. The bride is wearing a long, white dress and the groom a black suit. Both the shape of the cake and the style and colours of the outfit are traditional and symbolic and can easily be recognized as wedding symbols in the European or American culture. In other cultures associations brought by the image do not have to be so unequivocal. The leaflet aims at leading the addressees' attention from the wedding itself to the costs it involves. Many a time throwing a wedding party means extra expenditures so financial support is needed.

The same banking product is advertised by the same bank with an image of a similar box, however this time the box is red with a Chinese little dragon painted on the front. The box is open and a huge colourful and richly ornamented head of Chinese dragon sticks out of it. For the Europeans China means a long trip to an exotic place on another continent, which involves considerable financial outlays. If this image was presented in China, the interpretation would certainly be different as China would not be perceived as a remote exotic place.

One of the banks promoting Visa Cards combined with mobile telecommunications services chose to advertise their offer by referring to a birthday tradition. The picture shows a young smiling girl wearing a pink ballet dress and pointe shoes sitting on a green coach trying to untie a red ribbon which decorates a green gift box. The girl's outfit is a fulfillment of a girlish dream to become a ballet dancer. The culture-specific aspects concern first the very idea of receiving birthday presents, and second having the present wrapped in a square box tied with a nice ribbon. Birthday is an event celebrated in a number of cultures, however, the idea and form of giving presents is not universal.

All of these specific images are interpreted within a particular cultural context. Therefore, they have to be carefully chosen as evoked associations may differ in different cultures and also in different business branches. 


\section{Qualisigns}

The last category that emerged from the analysis of research material are images described as qualisigns. A qualisign may be defined as "a sign that draws attention to qualities possessed by the referent" (Danesi, 2002: 9). It frequently functions as a symbol or a visual metaphor determined by cultural experience. Therefore, the group of qualisigns encompasses images which seem to be unrelated to banking industry such as:

- an ostrich - a bird symbolizing speed, metaphoric meaning: fast as an ostrich, advertising a cash loan available in a quarter of an hour;

- a magic wand - a symbol of fulfilling wishes, an object present in fairy tales, devoid of any real function, an advertisement of a cash loan;

- a lighthouse - associated with navigating, showing direction to those in the sea (a cash loan);

- seating furniture - connoting with comfort, relief, in one advertisement two armchairs are placed centrally, one of them is antique and the other one modern, both giving an impression of being very comfortable and inviting - alike the account they advertise;

- a shield - a symbol of protection and defense, it is used in order to ensure that the monthly instalments will be the lowest possible (a cash loan).

- a dandelion clock - referring to lightness of instalments (a credit card).

The analysis of qualisigns clearly shows that the attributes of the images used in banking advertisements are supposed to evoke associations related to banking products and financial industry. They present services and products through visual metaphors.

\section{Conclusions}

The aim of this paper was to show how signs can be translated through social semiotics. The conducted research has shown that abstract notions in advertising can be expressed through tangible objects. In order to present such intangible ideas such as loans or mortgages proper organization of certain objects in an advert is necessary. On the level of denotation, these objects included predominantly coins, banknotes or credit cards and their arrangement proved meaningful as well. Furthermore, the analysis showed that activities are referred to with the use of connotations evoked by certain motifs serving as symbols. An attempt has been made to distinguish the most common actions concerning money, which are present in advertising leaflets, and 5 such actions have been identified, i.e. saving, growing, investing, transferring and spending. 
Visual communication and the symbolic use of signs help to create an attractive formula and enrich the design of advertisements. The creation of an informative and successful advertising appeal must also be based on cultural context. It turned out that the knowledge of culture and conventions is one of the basic requirements that have to be met in order to understand the message. It is particularly important as some of the presented object could gain different meaning in different cultural framework or when placed in adverts of other businesses.

The process of meaning making was crucial in our analysis, hence the semiotic approach was applied. The tool of the analysis has assumed the form of a matrix. Each element of this matrix, whether it is denotation, connotation, cultural context, or qualisign, contributes to the creation of the message. Although the present research analyzed advertisements from banking sector, the matrix used in this study can be applied in any other area. However, an assumption can be posted that the suggested matrix does not have to be confined only to 4 elements. It can expand if analyzed material, from other fields, reveals additional crucial aspects.

\section{References}

Bendykt, A. 2005. Reklama jako proces komunikacji. Wrocław: Astrum.

Bignell, J. 2002. Media semiotics: an introduction. Manchester: Manchester University Press.

Cobley, P. 2010. The Routledge companion to semiotics. Abington: Routledge.

Cook, G. 1992. The discourse of advertising. London: Routledge.

Danesi, M. 1994. Messages and meanings: an introduction to semiotics. Toronto: Canadian Scholars' Press.

Danesi, M. 2002. Understanding media semiotics. London: Arnold.

Durant, A. and M. Lambrou. 2009. Language and media. London/New York: Routledge.

Dyer, G. 1982. Advertising as communication. London: Routledge.

Hofstede, G. and G.J. Hofstede. 2005. Cultures and organizations. Software of the mind. New York: McGraw Hill.

Jewitt, C. and R. Oyama. 2004. "Visual meaning: a social semiotic approach". In: Leeuwen, T. and C. Oyama. (eds.). Handbook of visual analysis. London/Thousand Oaks/New Delhi: Sage Publications. 134-156.

Kress, G. 2010. Multimodality: a social semiotic approach to contemporary communication. London: Routledge.

Kress, G. and T. van Leeuwen. 1996. Reading images: the grammar of visual design. London: Routledge.

Kwarciak, B. 1999. Co trzeba wiedzieć o reklamie. Kraków: Wydawnictwo Profesjonalnej Szkoły Biznesu.

Najafian, M. and S. Ketabi. 2011. "Advertising social semiotic representation: a critical approach". International Journal of Industrial Marketing 1.1. 63-78.

Puppel, S. 2010. „Zarys modelu komunikacji w obrębie dwubiegunowego Uniwersum Znakowo-Językowego (UZJ)". Oikeios Logos Nr 7. 1-5.

Puppel, S. 2013. “A communication manifesto (evolving)”. In: Puppel, S. (ed.). Scripta Neophilologica Posnaniensia XIII. 91-100. 
Saren, M., Maclaren, P., Goulding, C., Elliott, R., Shankar, A. and M. Catterall. (eds.). 2007. Critical marketing: definining the field. Oxford: Elsevier.

Van Leeuwen, T. 2005. Introducing social semiotics. London: Routledge.

\section{Internet sources:}

IS1 Chandler, D. 1994. Semiotics for beginners.

Retrieved from http://www.aber.ac.uk/media/Documents/S4B/semiotic.html 